\title{
Toward generalized decision support systems for flood risk management
} Marian V. Muste ${ }^{1, a}$ and Ali Reza Firoozfar ${ }^{2}$

\author{
${ }^{1}$ Research Engineer and Adjunct Professor, IIHR-Hydroscience \& Engineering, The University of lowa, lowa City, lowa 52242, USA \\ ${ }^{2}$ Postdoctoral Research Scholar, IIHR-Hydroscience \& Engineering, The University of lowa, lowa City, lowa 52242, USA
}

\begin{abstract}
Despite the emergence of a large number of specialized decision-support systems (DSS) in the last decades, currently there are fewer efforts made for integrating the flood risk management relevant sciences with information and communication technologies into generalized DSS. Such systems are expected to formulate decision options for prevention, mitigation, preparation, response, and recovery from flood impacts with consideration of climate change, socio-economic evolution, and stakeholders' input. Currently, there is no unified vision on the architecture, components, and the needed computer and communications technologies for attaining generic DSS for flood mitigation and resilience. Moreover, there is no guidance of what components should be developed first and in what order and how to efficiently include human-computer interfaces for efficient stakeholder engagement and consensus. This paper calls for the formation of a strategic global partnership for framing and subsequently assisting in the development of a generalized flood DSS (FLOODSS) that can overcome the current flood DSS limitations. The call is preceded by a review of the flood decision-support terminology and context. Subsequently, an initial vision on the FLOODSS is outlined and the steps for transitioning such a system from vision to practice are proposed.
\end{abstract}

\section{Introduction}

Floods in coastal and inland areas have become increasingly common in recent years, impacting public safety, the economy, and the environment. The 2014 Flood Loss Averages for the U.S., released by the National Oceanic and Atmospheric Administration's National Weather Service, shows there were \$7.96B/year in damages over the past 30 years (www.nws.noaa.gov/hic). The increasing trends were also observed in Europe and Asia [1]. While these economic losses topped \$200B worldwide in 2014 (equivalent to a mid-level country GDP), the thousands of deaths and millions of people displaced from their homes each year are even more devastating. These enormous socio-economic damages are unlikely to diminish as changes in the global climate and land use practices are drastically altering the hydrologic cycle, yielding a global increase in flood frequency [1].

At a time of unprecedented growth in the number of large floods in many regions of the world, there is an increased recognition of the need for moving toward integrative approaches to flood-risk management whereby the flood-related processes are perceived as a whole system [2-5]. Development of decision-support systems using these approaches requires deep and wide integration of an unprecedented volume of data and information generated by surveying, monitoring with multi-domain modeling (hydro-meteorological, socioeconomic and ecological) into informatics-based systems that can in turn produce actionable knowledge for

\footnotetext{
${ }^{a}$ Corresponding author: marian-muste@uiowa.edu
}

practice through multi-criteria analysis of the flood-risk management scenarios [6, 7]. Currently, the water resources, and emergency management agencies face daunting challenges in (i) assembling the information needed to guide flood risk management, (ii) formulating flood risk mitigation and recovery plans, and (iii) delivering timely customized information to stakeholders experiencing flooding.

It seems, however, that attaining efficient flood risk prevention and building flood resilience in many practical situations is not so much challenged by the lack of basic hydrologic/hydraulic science or tools for the evaluation of flood hazards and risks, rather than the lack of operational platforms needed for managing risk [8]. Such platforms should handle multi-purpose information, communicate with stakeholders and engage them in the decision-making process. Despite the emergence of a large number of specialized decision-support systems (DSS) in the last decades $[9,10]$, there are fewer efforts made to integrate the flood risk management relevant sciences with information and communication technologies into generalized DSS capable of formulating decision options for prevention, mitigation, preparation, response, and recovery from flood impacts with consideration of climate change, socio-economic evolution, and stakeholders' input. Currently, there is no unified vision on the architecture, components, and the needed computer and communications technologies for attaining generic DSS for flood mitigation and resilience. Moreover, there is no guidance of what components should be developed first and in what order and how to 
efficiently include human-computer interfaces for efficient engagement and consensus of the stakeholders.

The main challenge associated with the creation of generalized DSS for flood stems in the fact that they are information and communication systems that are built for, and dependent on, a specific application domain. The conceptualization and design of a decision-support system for flood risk have to solve intricate interdependencies among engineered systems and the natural world with some of them not fully understood. More specifically, building efficient DSS require the development of cyberinfrastructure components (databases, web services, and computational algorithms) that are customized for ingesting and handling in realtime information produced by hydro-meteorological and socio-economic models used for estimating flood hazard and risk. Some of the information is not strongly structured leading to obstacles in the machine-to machine communication. Additional challenges are related to design the DSS with a user-centered, interactive approach whereby users, their characteristics, and contexts are incorporated in system architecture [11]. Intrinsic variability across the human population is associated with variable responses to environmental stressors. Understanding both the sources and the magnitude of the variability is a key challenge for scientists and for decision makers.

It is obvious that addressing such challenges extends well beyond the reach of a single-discipline group, specialized institute or even nation. It requires conceptualization efforts followed by coordinated research and technological developments at a global scale with the involvement of all relevant flood mitigation stakeholders (national and local executive institutions, private business, academia, public and communities). Such an ambitious endeavor can only be attained through the formation of a trans-disciplinary and transinstitutional collaboration with international dimensions.

This paper calls for the formation of a strategic global partnership (SGP) for framing and subsequently assisting in the development of a generalized flood decisionsupport system (called herein FLOODSS) that can overcome the current DSS limitations. The present conference is a good opportunity to launch such a call as it brings together academic researchers, governmental agencies, and industrial DSS developers under one roof. The call intention is to assemble a core group of international collaborators whom are charged to set the foundation of a long-term global partnership to target the transfer of flood science, research products, and technologies into commercially available decision- support systems (DSS) focused on floods. The overarching FLOODSS goal is to empower decisionmakers and local communities with the enabling technologies for timely preparation and mitigation of flood impacts while retaining sustainable development and the benefits of living near waters.

The paper is organized as follows. First the terminology on which FLOODSS is based along with the current flood risk management context is described. Subsequently, a statement of the FLOODSS vision and the description of the potential system architecture and its components are discussed. Initial FLOODSS workflows are also illustrated. Finally, broad steps of the road map for transitioning FLOODSS from vision to practice are suggested.

\section{Setting the FLOODSS context}

Driven by advancements in flood sciences, the terminology for decision-making domain has continuously progressed leading to a gradual change in the depth and breadth of the terms. Given the importance of precise terminology in the construction of a decisionsupport system, the central terms for defining the FLOODSS vision are provided below. The terms and concepts proposed for adoption in the design and development of the operational features of FLOODSS are drawn from recent definitions of the United Nations' Sustainable Development Goals (http://sustainabledevelopment.un.org) and Sendai Framework for Disaster Risk Reduction (http://www.unisdr.org/we/coordinate/sendai-

framework), as well as from reports of the Intergovernmental Panel on Climate Change (http://www.ipcc.ch) as they are considered to reflect the most updated understanding of decision making concepts. For consistency and accuracy, the selected terms are replicated verbatim in Table 1 .

Central to the FLOODSS approach should be the focus on flood risk rather than flood hazards. This approach contrasts with the conventional one whereby structural flood-mitigation measures were designed to withstand specific level of hazards (e.g., 20-year, 100year, 250-year, etc.). Using risk rather than hazards as management goals implies that people and societies may perceive or rank risks and potential benefits differently, given their diverse values and goals at a given time (e.g., $[12,13])$. These perceptions affect many aspects of the flood adaptation and mitigation, which in turn calls for DSS that can be adapted in space and time to fit the local conditions.

\begin{tabular}{|l|l|}
\hline Hazard & $\begin{array}{l}\text { The potential occurrence of a flood event that may cause loss of life, injury, or other health impacts, as well as damage or } \\
\text { loss to property, infrastructure, livelihoods, service provision, ecosystems, and environmental resources. }\end{array}$ \\
\hline Exposure & $\begin{array}{l}\text { The presence of people, livelihoods, species or ecosystems, environmental functions, services, resources, infrastructure, or } \\
\text { economic, social, or cultural assets in places and settings that could be adversely affected by floods. }\end{array}$ \\
\hline Vulnerability & $\begin{array}{l}\text { The propensity or predisposition to be adversely affected by floods. Vulnerability encompasses a variety of concepts } \\
\text { including sensitivity or susceptibility to harm and lack of capacity to cope and adapt. }\end{array}$ \\
\hline Risk & $\begin{array}{l}\text { The potential for consequences where something of value is at stake and where the outcome is uncertain, recognizing the } \\
\text { diversity of values. Risk is often represented as probability of occurrence of hazardous events or trends multiplied by the } \\
\text { impacts if these events or trends occur. }\end{array}$ \\
\hline & Risk results from the interaction of vulnerability, exposure, and hazard.
\end{tabular}

Table 1. Key terms used in the FLOODSS design (adapted from [14]). 
The decision-making for floods cannot be made by isolating the hydrologic-hydraulic drivers and the other flood-related processes from their regional and global context. Consequently, the decision-making has to account for time evolving climate variability as well as the human development in various areas of activities. This is especially important for a generalized DSS with the role of flood prevention. Figure 1 captures the connections between risk and external stressors such as climate change and human development.

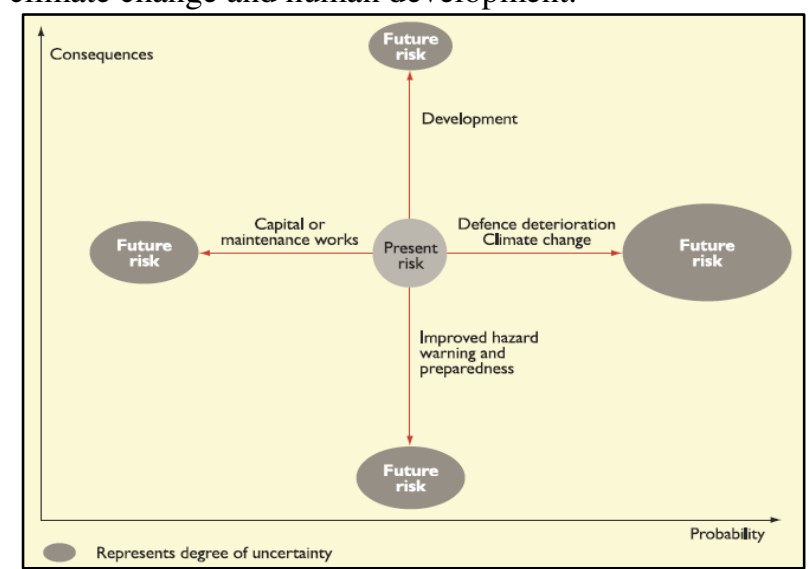

Figure 1. Flood risk increase with changes in the natural systems and time-evolving human development [2].

Another central feature of the FLOODSS should be the capability to convey data and information to stakeholders affected by floods with a high degree of confidence for ensuring credibility for the decisionmaking process as well as for policy analysis and formulation. Assessing the quality for data and information is often interchanged with estimating their uncertainty. Guidance in implementing decision-making under uncertainty is in progress $[15,16]$. Currently, efforts are made to identify, adopt or develop comprehensive frameworks for rigorous assessment of uncertainty analysis in hydrologic measurements (e.g., [17]), flood modeling as applied to hydro-meteorological processes and associated tools [18,19], and flood-risk management process as a whole [15]. The latter framework is obviously the most complex as assumes estimation of uncertainties associated with the data, models and other tools integrated in the description of the whole flood system from cause to consequences, along with the uncertainties of the prevention measures and of the decision making process itself [2].

Finally, the FLOODSS should account for the cyclic nature of the flood-risk management [20]. The main steps of the cycle are centered on the pre-flood, during, and post-flood activities, i.e., prevention, protection, preparedness, emergency response, and damage recovery. Effective management assumes that equal attention is given to each of these activities, although local conditions may require to emphasize some activities over others. The cycle is not actually a circular sequence of repeated actions, rather it is a spiral reflecting a continuous time evolution of the management process that allows to incorporate new gains in the understanding of the observed and modeled processes and the inclusion of additional mitigation measures that are adopted over time in the areas exposed to floods [4]. The availability and access to scientifically based tools for flood-risk management can be infused at any time during the cycle as soon as those tools become available.

\section{Status of DSS for floods}

Decision making for flood risk involves a hierarchy of management actions spanning a range of temporal and spatial scales, jurisdictions, and stakeholders, as illustrated in Table 2. The largest spatial scales can be continental (for decisions in trans-boundary rivers) while the smallest temporal scales can be of the order of hours (for real-time decisions associated with flood warning). The stakeholder spectrum is also broad, ranging from international and governmental institutions to community-based organizations; from private sector industry and financial institutions to academia and civil society. The DSS platforms have to assist various steps in the decision making on flood-related aspects from near real-time delivery of the information to long-term projections and scenario analyses.

Given the variety of the types of decisions to be made, defining the DSS with a single and precise definition is challenging [10]. The terminology invoked in defining DSS for floods includes:

a) computer-based systems

b) data management and sharing systems

c) simulation models,

d) tools for decision analysis, and,

e) user interfaces for connecting tools and people and visualizing the data and information during decisionmaking process

The concept of DSS emerged in the 1970's in connection with the wider use of computer-based systems for dealing with semi-structured and unstructured problems [10]. The unstructured nature of the flood management process derives from the intrinsic complexity of the hydro-meteorological system, the challenge of selecting the appropriate modeling tools, the perception of the flood risk by stakeholders, the prioritization of competing objectives, and the challenge in the selection and assessment of decisions.

Taking advantage of the availability of complex computer-based simulations of flood-related processes (that could be easily coupled with analysis, inference, and visualization tools), the initial DSS for flood management were almost exclusively of the model-driven type for testing alternative management scenarios [21]. These models include hydro-meteorological processes, hydrologic-hydraulic processes, socioeconomic and environmental impact assessments as well as management and optimization schemas (linear programming, dynamic programming, multiple criteria decision making, genetic algorithm, risk assessment, etc.). The models fitted with interfaces were labeled as DSS even though they were developed as stand-alone applications therefore leading to disillusionment about how such systems can assist decisions in a multidisciplinary and interdependent area of flood management [10]. 


\begin{tabular}{|l|l|l|l|}
\hline \multicolumn{1}{|c|}{ Decision } & \multicolumn{1}{c|}{ Jurisdiction/Stakeholder } & \multicolumn{1}{c|}{ Spatial scale } & \multicolumn{1}{c|}{ Temporal scale } \\
\hline Transboundary and national & International, governmental institutions & $\begin{array}{l}\text { River basin, } \\
\text { nationwide }\end{array}$ & Decades to annual \\
\hline Inland or coastal watersheds & Local government, flood-related institutions & Regional watersheds & $\begin{array}{l}\text { Decades with 5-year } \\
\text { reviews }\end{array}$ \\
\hline Development control & $\begin{array}{l}\text { Regional and local public institutions and } \\
\text { communities }\end{array}$ & $\begin{array}{l}\text { Regional, local } \\
\text { watersheds }\end{array}$ & Decades \\
\hline $\begin{array}{l}\text { Project appraisal and design } \\
\text { current \& future) }\end{array}$ & $\begin{array}{l}\text { Business, regulators and financial } \\
\text { institutions }\end{array}$ & $\begin{array}{l}\text { Catchment to } \\
\text { individual plot }\end{array}$ & Decades \\
\hline Maintenance \& Operation & $\begin{array}{l}\text { Regional and local flood-defense \& } \\
\text { operative bodies }\end{array}$ & Regional to local & Hours \\
\hline Risk communication & Communities, individuals & Regional, local, plot & Years to days \\
\hline Flood warning & Flood-warning agencies & Regional to local & Hours \\
\hline
\end{tabular}

Table 2. Type of flood risk management decisions (adapted from [15]).

Gradually, the existing models were assembled in customized information system frameworks for fulfilling specific requirements of the decision-making process and support the workflow of authorities [22]. This integration led to DSS for specific purposes such as:

- Strategic planning and management (e.g. $[23,24])$

- Flood forecasting (e.g. [25, 26])

- Flood hazard mapping (e.g. [27, 28])

- Emergency planning/warning system (e.g. [29, 30])

- Post flood recovery/damage evaluation (e.g. [31])

- Risk mapping (e.g. [9, 32])

- Emergency management (e.g. [24, 33])

-Multi-criteria analysis (e.g. [34, 35])

Currently, significant improvements have been obtained from integrating methodological approaches pertaining to three different domains: modelling, decision analysis, and participatory planning [21, 36]. An illustration of the integration of the three aspects of the decision-making process is provided in Figure 2. While not always successful, accepting the challenge of combining these methodological approaches in one framework promises to increase the DSS potential in flood as well as any other area of natural resources management.

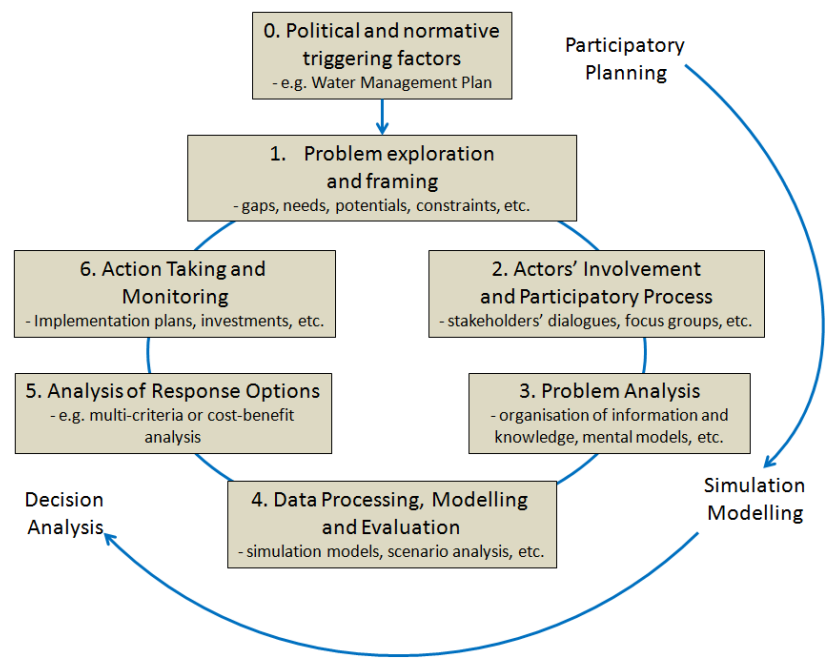

Figure 2. Contemporary DSS for floods integrate stakeholders' participation in planning activities by providing them with access to simulation modeling and decision analysis [21].

The persistence of the flood threat at global scale, indicates that the level of integration and skills of the contemporary DSS are not sufficient despite of the sustained research efforts [37]. Moreover, there is a general perception that by simply combining advances in flood science, information technologies, and communication technologies is not sufficient to fulfill comprehensive and stringent national and international regulations such as the European Water Framework Directive $[10,38]$. There is a recognized need that water managers have to adopt new practices, including participatory approaches to the decision-making along with appropriate training and maintenance of the DSS [10, 38].

In parallel with the development of the methodological aspects of DSS for floods, progress has been made on the technological side. This area, collectively labeled herein as supporting cyberinfrastructure or informatics, is an active area of research and development [37]. The technological aspects of the DSS include all operational aspects of the management process, including system interoperability and data exchanges, use of enterprise geographic information system (eGIS) and geo-Intelligence, acquisition and management of observations, coupling data with models, and integrating simulation models in truly collaborative modeling platform [8]. Contemporary DSS cannot be any more developed without web-based or web-enabled components. Web-based DSS design implies that the entire application is implemented using Web technologies (e.g., Web server, HTML, CGI, PHP, relational databases such as Postgres or MySQL). Reviews of Web DSS demonstrates that they revolutionize the decision-making process by integrating in one virtual hub data-, model-, knowledge-, and document-driven business processes [37].

Adopting a web-based design for DSS allows to access multiple resources using web technology (even if they are widely distributed geographically) and displaying them in a browser on the user side. In such systems, most of the hydrologic data and information used for formulating decisions remain on a legacy system maintained by the data providers except for the application c (e.g. [40-42]). Similarly, the geospatial and remote sensed datasets can be accessed, processed, and subsequently feed into hydrologic models using webbased tools (e.g. [43]). The most advanced web-based modeling environments facilitate multi-user activities whereby developed models can be published, run remotely using efficient high-performance computing 
while the simulation results can be selectively retrieved and visualized for further sharing (e.g. [44,45]). Without relying on any local modeling or computational resources, users with interests in the same geographical area and larger-scope problem (Such as flooding) can use the platform for collaboration even if their end objectives differ from those of other users.

These advancements in the DSS operational technology are mostly related to the use of web services, a concept defining a reusable computer application that allow machine-to-machine communication using standard protocols over the internet (http://wikipedia.org). Use of web-services allow users to tackle decision-making with multiple models developed by different sources and aggregate and summarize the outcomes for preparing decision alternatives. Within web-based DSS, each model works as an independent expert called upon to provide assistance in the form of a web service [46]. They have been increasingly gained acceptance as commercial products in important competitive areas of economy (e.g. $[36,47])$.

Attaining the level of operational capabilities and performance needed for efficient flood-risk management implementation may appear daunting as the amount of data from observations and simulations are vast, the cross-disciplinary workflows are complex, and the actors involved in the decision-making process are both numerous and technically diverse [4]. The main challenges in developing a high-performance DSS are that domain scientists lack the skills to effectively manage, curate, and preserve large volumes of digital data and the skills to develop software that connects it through workflows in the digital domain. Such skills are specific to data professionals with a strong computer programming background who rarely fully understanding specific needs that earth science data entails.

Likewise, there is an increased need for information and communication scientists who are capable to engage in the flood-focused public discourse. These experts interpret science for and engage various stakeholders (e.g., policy makers, public officials, and citizens), build and share actionable knowledge with contemporary communication and interaction tools (e.g., social networks, e-media, mobile technology, and digital mapping) to ensure a broad participatory decision-making process. An illustration of the high-level cyberinfrastructure of the technological flow specific to flood risk-management is provided in Figure 3.

Irrespective of the degree of methodological and technological complexity embedded in the DSS, an important clarification to be made right upfront is that even the most sophisticated DSS are not intended to provide definitive decisions for a specific situation or to replace decision makers altogether. Actually, it has been demonstrated that the proper implementation of DSS by different users can produce different results [48]. However, the use of DSS can effectively assist decision makers with options, facilitate communication of different views and preferences, build a consensus, and potentially resolve conflicts.

Overall it can be concluded that the adoption of webbased approaches for the platforms has the potential to elevate the DSS capabilities at new, unprecedented operational levels. Moreover, the web-based approaches can uniquely accommodate the community desire to tackle flood risk management with new bolder methodologies such as it the consideration of the flooding as a whole system, from causes to consequences with consideration of the multi-faceted flood-risk decisions.

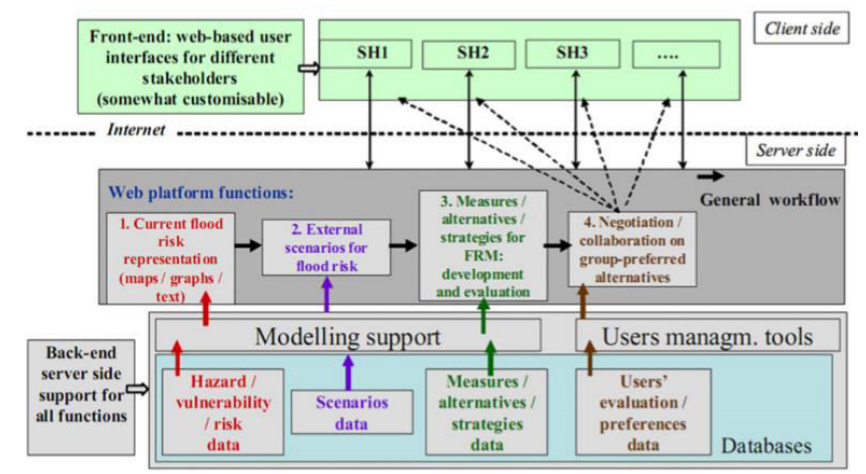

Figure 3. Conceptual design of a flood-risk management webbased platform. These platforms enable simultaneous multi-user access that facilitate the collaborative modelling process that is

perceived as joint learning process involving FRM experts, authorities and stakeholders, critically supported by models and modelling results [32].

Nevertheless, the web-based DSS are well positioned for facilitating multi-participant interactions and efficient accounting of the stakeholders' context, needs, abilities, and preferences. Collectively, the advance in the methodological and technological aspect of contemporary DSS empower decision makers with skills that shed unprecedented insights into the flood-problem drivers and the policy outcomes while facilitating communication and knowledge transfer among the actors involved in or affected by decisions [10].

Following the successful implementation of early proof-of-concepts DSS developed in the water resources community, it has been proposed to adopt the digital observatory framework concept for flood risk management [5]. The digital observatory (DO) is a webbased integrated science-research-management approach for tackling water resources management problems using methodological principles of the integrated water resources management [4]. DOs are electronic representations of watersheds and their processes as documented the spatiotemporal representation of the data, simulation models, and the analyses and syntheses of the available data and information. DOs must embrace the best available information to provide the digital description of the natural environment and the man-made constructed infrastructure (e.g., dams, water abstraction, and discharge systems) using a variety of data sources. DOs comprise data servers and software tools that aggregate third party data acquired by various federal and state agencies with local data (including academic settings) in a system that is open, easy to use, and enables integrated analysis and modeling. Although the acquisition of data and the development and application of models have been typically tasks for expert scientists and engineers, managers are now requiring online access 
to such data and information for supporting the decisionmaking process. DOs can provide a good starting point in exploring potential frameworks for FLOODSS development. Proposed next is the road map to engage in the FLOODSS development partnership.

\section{Current FLOODSS vision}

FLOODSS is envisioned as an interactive softwarehardware platform that assembles in one place a mix of existing and customized software models and tools (for aggregating various hydro-meteorological data, hazard mapping, economic losses, risk mapping, linking models, visualizing scenarios, etc) and computer and communication technologies to facilitate the presentation of decision-making outcomes (i.e., intervention alternatives assessed for financial and societal aspects) into a language understood by all stakeholders. FLOODSS is fit with the data handling and multidisciplinary modeling needed for managing risk of floodfocused systems irrespective of their spatial extent and temporal resolutions.

Setting the conceptual framework for the FLOODSS web-based platform is both ambitious and challenging as such a system has to be designed in close correlation with the structure of the information produced by process monitoring, modeling, documenting, and stakeholder communications. The dominant process of the FLOODSS is the multi-disciplinary modeling that leads to creation of the flood risk maps. The design and implementation of a model-driven DSS has to address many issues that are still unresolved. Among them are the storage and retrieval of data needed by different types of models, communication of parameters between models and the other DSS components, enabling multi-participant interventions in model usage and risk assessment, and building interfaces that can be effective and easy to use [39].

It is obvious that this broad list of needs is daunting and calls for community effort, which is the main message of this paper. Some key elements of the vision are provided below to substantiate the topics that require future discussions and research. This vision is in an incipient phase and it is the result of the authors' prior experience in flood problem solving, development of cyberinfrastructure platforms, and substantiated by a recent critical review of the advancements in the DSS area for natural resources management.

The overall FLOODSS role would be to provide decision-makers with resources (data, information, domain knowledge) and procedures to formulate alternative outcomes, assess trade-offs and identify solutions that meet the priority objectives. Besides supporting the modeling leading to flood hazard mapping, the activities supported by the platform that are more-closely related to the decision-making process include:

a) assisting in planning for flood prevention and recovery (i.e., "build back better" approach)

b) assisting during flood crises c) engaging communities in the planning process to reduce risk exposure

d) educating communities on the capabilities and limitations of structural and non-structural mitigation measures

e) shedding new insights in flood science for learned practitioners, and,

f) informing stakeholders on how prevention and response capabilities enhance resilience (by reducing overall risk exposure and having responses in place when design levels are exceeded).

The main FLOODSS users could be the regional and local flood risk managers, flood-focused mitigation groups, and communities with high flood-risk exposure. The integration of the multi-domain data and information into a "one-stop shop" accessible via the Internet creates a new paradigm not only for managers and communities with high flood-risk exposure, but also for scientists and researchers who are continuously seeking for new research opportunities. The availability of such a system will enable interdisciplinary flood research teams to uncover and investigate together the subtler aspects of flood risk management science that are currently rendered invisible by our limited capability to access, visualize, and analyze massive amounts of data and information describing flood-related processes from disparate sources.

The main FLOODSS functional features would be to enable access to widely-available resources (e.g., DEM, hydro-meteorological datasets and open-source modeling tools for processes involved in risk assessment) and management protocols and regulations formulated by specialized agencies (e.g., floodplain and emergency management, insurance industry). Additional features would allow to adjust the platform to local project needs irrespective of their environment (urban, rural, coastal or mountainous area) or specific flood-related aspects (debris flows, ice jamming).

The FLOODSS platform should be scalable, interoperable, and capable to provide greater assurances of safety and security under limited local resources (e.g., ungagged basins). The connection between the cyber and physical system components should be seamless and computer platform independent while ensuring ease of use and transparency for all category of users (from scientist to citizens), and expansion of functional options as new components become available. Fulfillment of this wide variety of requirements can only be obtained by a generalized DSS architecture - which is the most challenging aspect of the FLOODSS development.

The generalized nature of the DSS is associated with both the methodological and operational capabilities requires by flood-risk management. The FLOODSS decision-making methodology would build on multi-disciplinary data, information, and models applicable to both strategic and operational decision making irrespective of the size of the catchment or basin. The type of data and information, models, decision-making tools, actions, and their connections within FLOODSS are visualized in Figure 4. Inclusion of the communities in the data and information block of the figure is intended to emphasize that the community 
input (i.e., concerns, goals, perceptions as well as any relevant data, information and knowledge that it might provide) is an integral part of the decision-making process. The connections between various resources visualized in Figure 4 are not exhaustive nor universally valid and they can run in series or parallel. For example, the climate change impacts are both the drivers of the flood extent and frequency but in the same time they influence the vulnerability of the infrastructure exposed to risk, as illustrated in Figure 4.

Generalized DSS would not rely on a single piece of software for the management of the whole decision process nor would provide a single approach for every possible decision. They will be rather built using a modular architecture compatible with open-source software and they will adopt a structured approach to decision making that will provide multiple outcomes to choose from [49]. The technological construct of the FLOODSS should account for the fact that flood-risk management is an iterative process, which is indicated by the outer circular connections between the blocks layout in Figure 4. This circular connection are timeevolving leading to a spiral trajectory for the management process that builds on previous efforts and adapts to new demands and needs over time [4].

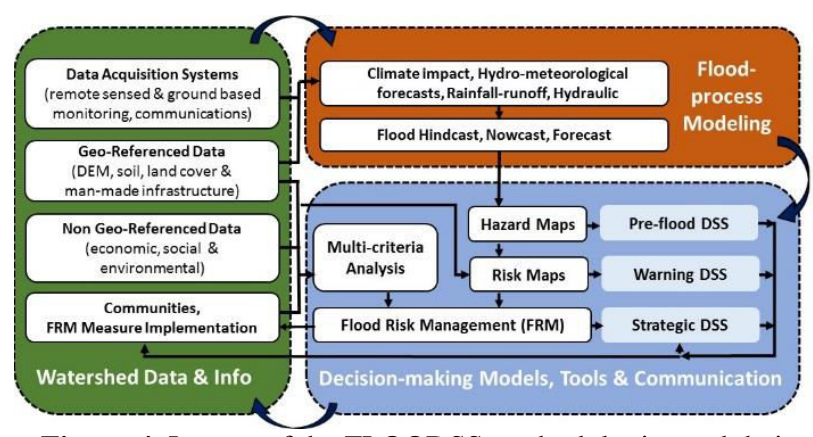

Figure 4. Layout of the FLOODSS methodologies and their interactions.

Irrespective of their scope (see Table 2), decisions related to floods revolve around hazard, exposure, and vulnerability concepts defined in Table 1 . To be effective, a flood-risk management approach has to be adopted relying on risk maps developed for various hazard levels for allowing the most appropriate actions during the progression of the flood. This approach is an important distinction from the conventional approach for flood management of the past whereby the mitigation standards prescribed the hazard level that a structural measure can sustain without considering the intrinsic exposure and vulnerability of the areal context.

Recognizing the human interference with the climate system and of the climate change on floods implies that flood mitigation has to also consider aspects of adaptation to climate change $[13,50]$. Adapting to the climate change trends is critically important at a time when it is observed that the extreme precipitation and streamflow are more frequent and larger in magnitude [51, 52]. Consequently the FLOODSS discussed in the present context would account for climate change and human development in the modeled scenarios, as illustrated in Figures 4 and 5. Such extraneous considerations complicate the methodological aspects associated with FLOODSS not only for problem formulation but for the solution exploration as well as the entail links between not quite fully understood links between human and natural systems.

The FLOODSS decision-making operational features should be designed to seamlessly integrate the data management systems, flood-related models, and the tools for flood-risk decision support in a web-based environment accessible by all stakeholders. A point of careful evaluation in the implementation of an open system such as FLODSS is to not convey publicly sensitive information protected by private property rights or competitive data pertaining to competitive institutions involved in flood mitigation (e.g., insurance companies). These issues have to be considered in strict agreement with the legal frameworks and institutional regulations possibly though aggregation of the confidential data at larger scale without losing their relevance to flood risk evaluation.

The system has to support the formulation of outcomes through repeated and simultaneous use of the system by many users, some of them with limited technical background. It is expected that the development of FLOODSS would greatly benefit from the ongoing research on Group Decision Support Systems (GDSS), an active area that addresses both technical and behavioral aspects (i.e., attitudes of the users vs. the functional features and outcomes of the DSS). The behavioral aspects are ultimately as important as the technical ones as many failures of DSS implementation are associated with the flexibility, ease of use, openness, and extensibility of the decision-making platforms $[10$, 39].

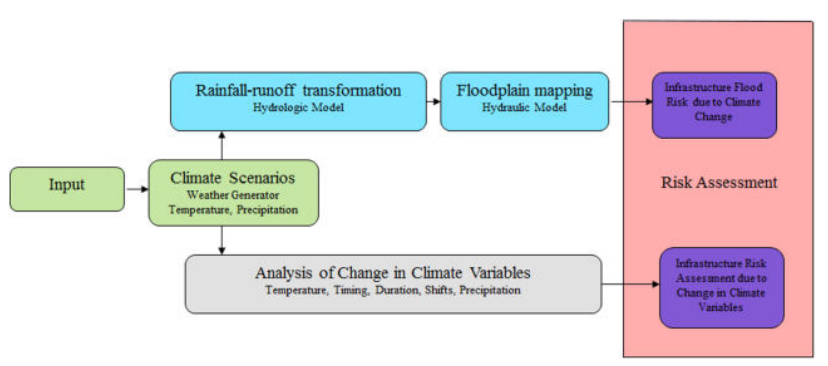

Figure 5. Flood-risk assessment with consideration of climate change impact [13].

The envisioned FLOODSS should not require any particular process or decision support software on the client computer. Ideally, the decision-support functionality should be delivered to users by a webbased, platform-independent system. Using the web browser, multiple users can change remotely the models' spatial and temporal inputs. This is in stark contrast with the practice of the conventional desktop-based modeling environment whereby a single user was accommodated at one time. The web-based approach allows simultaneous intervention from, for example, researchers and policy makers as both are interested in problem solving. The FLOODSS framework should allow for models to evolve around the "access - refine - re-run" pathway envisioned by Loucks et al. (1985) whereby a single model for a 
particular geographic location can be manipulated and analyzed differently by various type of users [53]. These capabilities are essential today as watershed science and management are increasingly collaborating in solving practical water problems. This collaboration is already mature for natural-scale observations and data (e.g., in situ observations, geospatial data sets, and remote sensing products) whereby data collected and freely disseminated by numerous federal, state, and local agencies are complemented by data acquired by academic scientists. Connecting science and management through FLOODSS can be far reaching.

Progressing from visions to implementation requires the conceptualization of the FLOODSS architecture. This effort can be phased over several steps:

a) formulating the workflows for linking the multidisciplinary processes

b) choosing the resources needed to inform the processes

c) choosing the tools to execute the modeling tools involved in the workflows

d) designing the specifications for the hardwaresoftware package that convey the information between the process components, and,

e) developing the interfaces for access, retrieval, visualization of the workflow outcomes.

Steps a), b), c), and e) mostly involve domain specialists. Steps d) and e) are typically tackled by cyberinfrastructure specialist who have garnered an understanding of the needs of the domain specialists. Figure 6 provides possible configurations of workflows for flood-risk analysis and decision making. The workflows are illustrated separately to highlight that they support decisions for short- and long-term activities related to flood mitigation. However, a closer look at the workflow components reveals their abundant similarities; i.e., most of the components in the two workflows are included in both systems (e.g., hydro-and hydraulic data and modeling leading to flood hazard maps). This commonality clearly illustrates the capabilities of a webbased system to integrate methodological and operational aspects for flood-risk management in one framework irrespective of their goals.

Clarifying of the role and functions of these workflows along with the evaluation of the data and other interactions within the workflows need discussion right at the onset of the FLOODSS development as they are critical for properly embedding them within the system. It is obvious that this process would require initial consultations between domain and information and communication specialists. Later on, these consultations will expanded for the inclusion of the whole range of flood mitigation stakeholders. Fortunately, our community has successfully launched similar calls for synergism in the past. The most relevant such community for the present context is the one built around the hydroinformatics concept created in early 1990s [55].

Water science and engineering was among the first natural science communities that came to the realization of the need for new informatics-centered approaches in addressing water problems. As a result, the basis of Hydroinformatics as a stand-alone technology were set as a cross-cutting across science effort focused on handling and managing data for producing information, knowledge, and services [55]. Soon after its inception, hydroinformatics has gradually become equivalent to the fourth pillar of scientific investigation besides the traditional ones (experiments, analytics, and numerical simulations).

Today, the hydroinformatics-based systems provide the technological components and the operational science and environment needed to increasingly close the gap between integrated water resources management theory and practice (www.iahr.org). The present call aims at creating the core alliance of stakeholders for making FLOODSS an integral part of the hydroinformatics community endeavors.

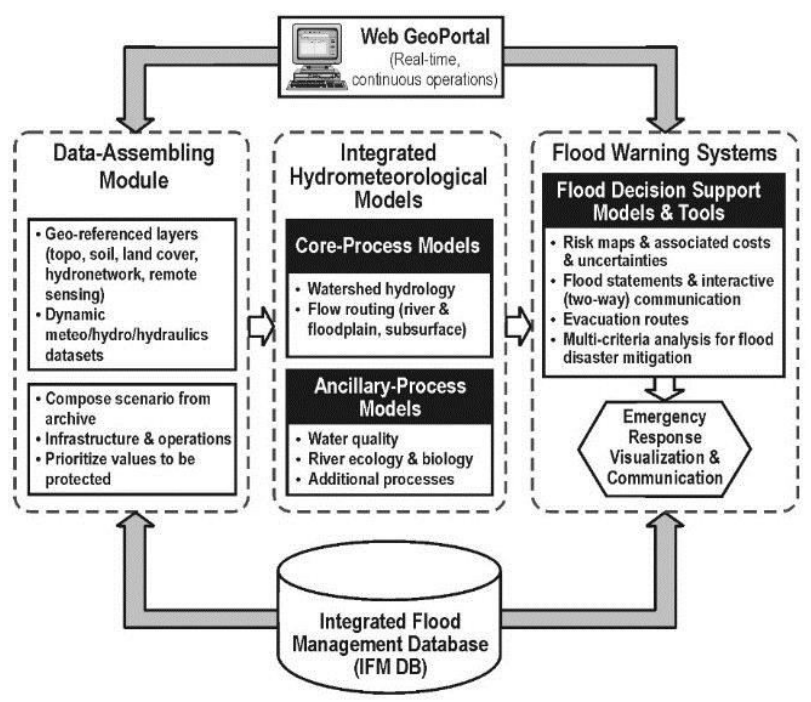

(a)

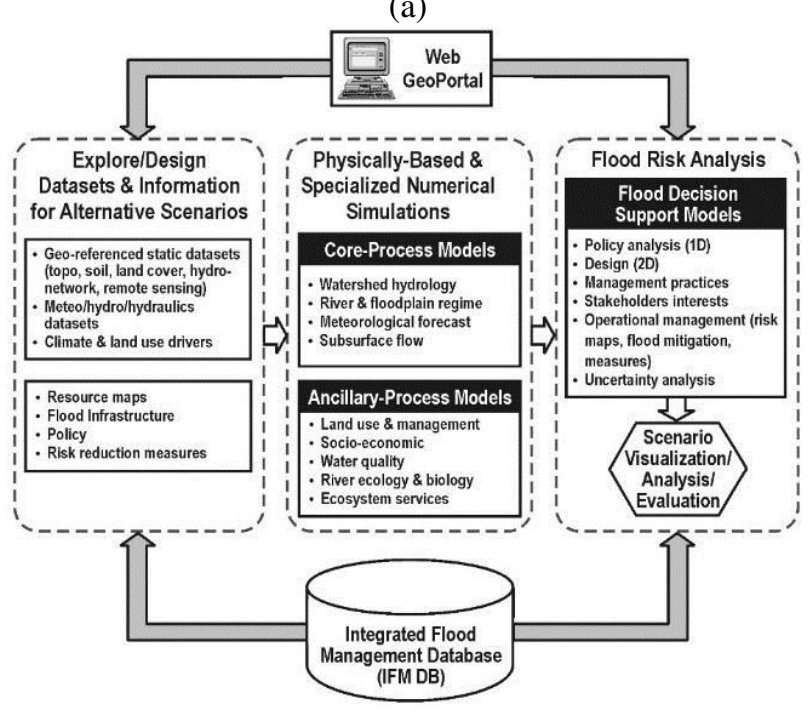

(b)

Figure 6. Layout of FLOODSS workflows for [54]: a) warning \& operations b) strategic planning

\section{FLOODSS development road map}

A wide collaborative effort is required to advance the FLOODSS vision. Most of the efforts are related to the assimilation of cyberinfrastructure that can: a) streamline massive amounts of information across geographic and 
institutional boundaries using interoperable systems and tools; b) integrate high-resolution information products and services on flood processes with flood-risk management practical aspects using service-oriented architecture; and, c) engaging stakeholders in the decision making process. The breadth and depth of FLOODSS vision extends well beyond the reach of a single research and development group, or even one nation. Thus, it requires the integration of capabilities and efforts at the global scale and a longer term commitment.

We propose a multi-institutional alliance of core partners that will overcome the current limitations of the flood-risk management DSS by setting the path for the assimilation of the necessary technologies in information and communication sciences to create a generalized, webbased platform for making decisions on flood mitigation and resilience. This alliance will aggressively search for the most advanced flood-risk management and cybersciences and technologies and subsequently develop specifications for a platform that can be quickly set in practice. The longer-term goal is to eventually convert FLOODSS into a commercially-available product.

To expedite and accelerate the development of practical FLOODSS the alliance will review promising ongoing efforts, will guide the development of methods, tools, and specific hardware and software components, and will identify end-to-end prototypes that can be validated through implementation in actual testbeds. For this purpose it is proposed to:

1. Identify and engage core strategic partners for FLOODSS development and implementation [water-focused professional communities (e.g., IAHR, IAHS, IWA), international scientific and applied sciences governmental agencies (e.g., WMO, UNESCO), specialized research centers (e.g., Wallingford Center, IFC - USA; IWHR - China, UNESCO/IHE - The Netherlands), industrial software producers and decision-support developers (e.g., DELTARES, DHI) are all essential partners for a robust development of the conceptual architecture, production process, and formulating of the business model for FLOODSS]

2. Set short-term and long-term development schedule backed up by formal collaborative agreements (for ensuring the sustainability of the FLOODSS initiative wide participation from governmental agencies, flood practitioners, universities, and industry is critical)

3. Formulate strategy for securing FLOODSS development funding [among the main potential partners for addressing this critical need are international non-governmental organizations (e.g., World Bank, GWP), international scientific agencies, applied sciences agencies (e.g., WMO, UNESCO), flood consulting and insurance companies, and private donors concerned with the flood-related disasters].

4. Elaborate an evaluation matrix for FLOODSS assessment (for ensuring a measure of a sustainable progress of the product development)

5. Identify early-stage DSS research that can act as proof-of-concept tests and allow inferences on further basic research needs. Encourage utilization of both academic and industry testbeds that facilitate transparency and openness to integrate research components suggested by the alliance.

6. Develop the conceptual architecture and the production process leading to an operational FLOODSS. (identification of existing components, producers, and early prototypes that are readily usable in the generic platform are essential for accelerating the overall development).

7. Consult with relevant stakeholders (governmental agencies, local communities, industry, and flood insurance agencies are expected to engage in the formulation FLOODSS operational requirements, supporting the implementation of proof-of concepts FLOODSS to specific testbeds as well as acting as developers for specific platform developments).

8. Develop a business model for sustained economic development of the FLOODSS [specifications of the means for attaining industrial production and commercialization (includes identification of the manufacturers, vendors, and distribution market) and intellectual property aspects]

9. Foster synergistic collaboration with mission agencies (key activity that has the potential to accelerate FLOODSS maturation, demonstration, and transition to practice).

\section{Closing remarks}

The review of relevant literature on decision-making and DSS for water resources and flood risk management has led to the conclusion that the initiation of a global partnership for strategizing, developing, and implementing a generalized decision-support system for flood is opportunistic for at least two reasons. First, there are many advancements in science and technology that are readily available for the construction of FLOODSS. Second, posing the statement of building FLOODSS is of paramount importance for flood mitigation and resilience efforts ongoing at the global scale.

Despite its exploratory nature, this paper strives to set a vision for launching a dialogue in the flood community on the opportunities, challenges, and the knowledge and technological gaps still obstructing the advancement of the cyber-physical systems into DSS for underpinning the efficiency and relevance of the decision-making in floodrisk management. It is hoped that the paper sets the stage for the creation of a hub for intellectual interactions and developmental actions toward bringing FLOODSS from concept to reality.

\section{Acknowledgements}

The support provided to the authors by The University of Iowa's Office of Research \& Economic Development and IIHR-Hydroscience \& Engineering's Iowa Flood Center made possible the preparation of this paper. 


\section{References}

1. IPCC (2014). Climate Change 2014: Synthesis Report. Contribution of Working Groups I, II and III to the Fifth Assessment Report of the Intergovernmental Panel on Climate Change [Core Writing Team, Pachauri R. K. and Meyer L. A. (eds.)]. IPCC, Geneva, Switzerland, pp. 151.

2. Sayers P., Hall J. and Meadowcroft I. (2002). Towards risk-based flood hazard management in the UK. Proceedings of the Institution of Civil Engineers: Civil Engineering, 50(5), pp. 36-42.

3. WMO (2006). Integrated Flood Management Concept Paper. Associated Program for Flood Management, Technical Document No.1, second edition, World Meteorological Organization, Geneva, Switzerland.

4. Muste M. (2014). Information-Centric Systems for Underpinning Sustainable Watershed Resource Management. Chapter 13 in Comprehensive Water Quality and Purification, Ahuja S. (Ed), Vol 4, Elsevier, pp. 270-298.

5. Mackay E. B., Wilkinson M. E., MacLeod C. J. A., Beven K., Percy B. J., Macklin M. G., Quinn P. F., Stutter M. and Haygarth P. M. (2015). Digital catchment observatories: A platform for engagement and knowledge exchange between catchment scientists, policy makers, and local communities. Water Resources Research, 51, pp. 4815-4822. doi: 10.1002/2014WR016824; 4815-4822.

6. Giordano R., Uricchio V. F. and Vurro M. (2008). Monitoring Information Systems to Support Integrated Decision-making. Timmerman J. G., PahlWostl C. and Moltgen J. (eds.), IWA Publishing, London (UK), pp. 113-129.

7. Cutter S. L., Barnes L., Berry M., Burton C.G., Evans E., Tate E.C. and Webb J. (2008).A Placebased Model for Understanding Community Resilience to Natural Disasters. Global Environmental Change, 18, pp. 598-606.

8. NOAA (2009). Integrated water resources science and services (IWRSS). An integrated and adaptive roadmap for operational implementation, IWRSS NOAA/ USACE/USGS Consortium.

9. Laine R., Cook C., and Lemass B. (2012). Decision support: Informing flood management. 52nd Floodplain Management Association. (pp 1-10).

10. Giupponi C., Mysiak J., Depietri Y. and Tamaro M. (2011). Decision Support Systems for water resources management: current state and guidelines for tool development, In: Vanrolleghem P.A. (Ed.), Decision Support for Water Framework Directive Implementation. IWA Publishing: London (UK), pp. 107-202.

11. Kramer J., Noronha S., and Vergo J. (2000). A usercentered design approach to personalization. Communications of the ACM, 43(8), 44-48.

12. Sayers P., Galloway G., Penning-Rowsell E., Yuanyuan L., Fuxin S., Yiwei C., Kang W., QuesneT. L., Wang L. and Guan Y. (2015). Strategic flood management: ten 'golden rules' to guide a sound approach, International Journal of River Basin

\section{Management, $\quad \mathbf{1 3 ( 2 )}, \quad$ 137-151, DOI:} 10.1080/15715124.2014.902378

13. Simonovic S. P. (2013). Floods in a Changing Climate: Risk Management, International Hydrology Series, Cambridge, UK.

14. Field C. B., Barros V. R., Mach K. J., Mastrandrea M. D., van Aalst M., Adger W. N., Arent D. J., Barnett J., Betts R., Bilir T. E., Birkmann J., Carmin J., Chadee D. D., Challinor A. J., Chatterjee M., Cramer W., Davidson D. J., Estrada Y. O., Gattuso J. -P., Hijioka Y., Hoegh-Guldberg O., Huang H. -Q., Insarov G. E., Jones R. N., Kovats R. S., Romero Lankao P., Larsen J. N., Losada I. J., Marengo J. A., McLean R. F., Mearns L. O., Mechler R., Morton J. F., Niang I., Oki T., Olwoch J. M., Opondo M., Poloczanska E. S., Pörtner H. -O., Redsteer M. H., Reisinger A., Revi A., Schmidt D. N., Shaw M. R., Solecki W., Stone D. A., Stone J. M. R., Strzepek K. M., Suarez A. G., Tschakert P., Valentini R., Vicuña S., Villamizar A., Vincent K. E., Warren R., White L. L., Wilbanks T. J., Wong P.P., and Yohe G.W. (2014). Technical Summary. In: Climate Change 2014: Impacts, Adaptation, and Vulnerability. Part A: Global and Sectoral Aspects. Contribution of Working Group II to the Fifth Assessment Report of the Intergovernmental Panel on Climate Change [Field C. B., Barros V. R., Dokken D. J., Mach K. J., Mastrandrea M. D., Bilir T. E., Chatterjee M., Ebi K. L., Estrada Y. O., Genova R.C., Girma B., Kissel E. S., Levy A. N., MacCracken S., Mastrandrea P. R., and White L. L. (eds.)]. Cambridge University Press, Cambridge, United Kingdom and New York, NY, USA, pp. 35-94.

15. Beven K. and Hall J. (2014). Applied uncertainty analysis for flood risk management, Imperial College Press, London, UK.

16. Hall J. and Solomantine D. (2008). A framework for uncertainty analysis in flood risk management decisions. International Journal River Basin Management, 6(2), pp. 85-89.

17. Muste M., Lee K. and Bertrand-Krajewski J-L. (2012). Standardized Uncertainty Analysis Frameworks for Hydrometry: Review of Relevant Approaches and Implementation Examples. Hydrological Sciences Journal, 57(4), pp. 643-667.

18. Matott L. S., Babendreier J. E., and Purucker S. T. (2009). Evaluating Uncertainty in Integrated Environmental Models: A Review of Concepts and Tools. Water Resources Research, 45(6), doi: 10.1029/2008WR007301, W06421, 14 p.

19. Kauffeldt A., Wetterhall F., Pappenberger F., Salamon P. and Thielen J. (2016). Technical review of large-scale hydrological models for implementation in operational flood forecasting schemes on continental level. Environmental Modelling \& Software, 75, pp. 68-76.

20. UNECE (2015). Flood risk management in transboundary basins. Discussion paper in the United Nations Economic Commission for Europe's Workshop on Transboundary Flood Risk Management II, March 19-20, 2015, Geneva. 
21. Giupponi C. and Sgobbi A. (2013). Decision support systems for water resources management in developing countries: learning from experiences in Africa, Water, 5, pp. 798-818.

22. GWP (2013). The Role of DSS and models in Integrated River Basin Management. Global Water Partnership.

23. Evans E. P., Ramsbottom D. M., Wicks J. M., Packman J. C., \& Penning-Rowsell E. C. (2002). Catchment flood management plans and the modelling and decision support framework. Proceedings of the ICE-Civil Engineering, 150(5), pp. 43-48.

24. Ahmad S., and Simonovic S. P. (2006). An intelligent decision support system for management of floods. Water Resources Management, 20(3), pp. 391-410.

25. de Roo Ad P. J., Gouweleeuw B., Thielen J., Bartholmes J., Bongioannini-Cerlini P., Todini E., Bates P. D., Horritt M, Hunter N., Beven K., Pappenberger F., Heise E., Rivin G., Hills M., Hollingsworth A., Holst B., Kwadijk J., Reggiani P., Van Dijk M., Sattler K. and Sprokkereef E. (2003). Development of a European Flood Forecasting System. International Journal of River Basin Management, 1(1), pp. 49-59.

26. Ibanez A. C., Schwanenbergm D., de Marcos L. G., Mahanud M. F. and Conzalez J. A. (2011). An example of flood forecasting and decision-support for water management in Spain. Proceedings of the $8^{\text {th }}$ International ISCRAM Conference, Lisbon, Portugal

27. CWCB (2006). Prototype Flood DSS. Colorado Conservation Board.

28. Maidment D. R. (2016). Planning for 2016 Summer Institute of National Water Center, National Flood Interoperability Experiment, Phase II, February 2, 2015, Tuscaloosa, TN.

29. Kang B., Lee J.-H., Hong I., Oh K. and Jeong S. (2010). Web-based assessment for flood forecasting and warning systems. Desalination and Water Treatment, 19(1-3), pp. 129-137.

30. Demir I., and Krajewski W. F. (2013). Towards an integrated flood information system: centralized data access, analysis, and visualization. Environmental Modelling \& Software, 50, pp. 77-84.

31. Todini E. (1999). An operational decision support system for flood risk mapping, forecasting and management. Urban Water, 1(2), pp. 131-143.

32. Almoradie A., Cortes V. J., and Jonoski A. (2015). Web-based stakeholder collaboration in flood risk management. Journal of Flood Risk Management, 8(1), pp. 19-38.

33. Georgakakos A. P. (2007). Decision Support Systems for Integrated Water Resources Management with an Application to the Nile Basin, In: Castelletti A., Soncini-Sessa R. (Eds.), Topics on System Analysis and Integrated Water Resources Management. Elsevier, pp. 99-116.

34. Jiang H., Eastman J. R., (2000). Application of fuzzy measures in multi-criteria evaluation in GIS. Int.
Journal of Geographic Information Science. 14, pp. 173-184.

35. FLOODsite (2009). Developing Methodological Foundations for GIS-based Multicriteria Evaluation of Flood Damage and Risk. Report T10=08-13, HR Wallingford, UK (available at: www.floodsite.net)

36. Sorensen H. R., Beyene M. and Ammentorp H. C. (2015). The Nile Basin Decision Support System. Hydrolink, 4, International Association for HydroEnvironment Engineering and Research, Madrid, Spain.

37. Firoozfar A. R. (2016). Literature review on floodrelated decision-support systems, IIHR Internal document provided by personal communication with the author.

38. EC (2003). Common Implementation Strategy for the Water Framework Directive (2000/60/EC), Guidance Document No. 8: Public participation in relation to the Water Framework Directive, Office for the Official Publications of the European Communities, Luxembourg.

39. Power D. J., Sharda R. (2007). Model-driven decision support systems: Concepts and research directions. Decision Support Systems, 43(3), pp. 1044-1061.

40. Tarboton D. G., Horsburgh J. S., Maidment D. R., Whiteaker T., Zaslavsky I., Piasecki M., Goodall J., Valentine D., and Whitenack T. (2009). Development of a community hydrologic information system. 18th World IMACS Congress and MODSIM09 International Congress on Modelling and Simulation, Modelling and Simulation Society of Australia and New Zealand and International Association for Mathematics and Computers in Simulation, pp. 988-994.

41. Horsburgh J. S., Tarboton D. G., Schreuders K. A. T., Maidment D. R., Zaslavsky I. and Valentine D. (2010). HydroServer: A Platform for Publishing Space-time hydro-logic Datasets. AWRA Spring Speciality Conference, Florida, USA, pp. 29-31.

42. Ames D. P., Horsburgh J. S., Cao Y., Kadlec J., Whiteaker T. and Valentine D. (2012). HydroDesktop: web services-based software for hydrologic data discovery, download, visualization, and analysis. Environ. Model. Software, 37, pp. 146156.

43. Wang S., Anselin L., Bhaduri B., Crosby C., Goodchild M. F., Liu Y., and Nyerges T. L. (2011). CyberGIS Software: A Synthetic Review and Integration Roadmap." International Journal of Geographical Information Science, 27(11), pp. 21222145.

44. Horak J., Orlik A., Stromsky J. (2008). Web Services for Distributed and Interoperable Hydro-information Systems. Hydrol. Earth Syst. Sci.,12, pp. 635644.

45. Rajib M. A., Merwade V., Kim I. L., Song C. and Zhe S. (2016). SWATShare - AWeb Platfrom for Collaborative Research and Education Through Online Sharing, Simulation and Visualization of SWAT Models. Environmental Modelling \& Software, 75, pp. 498-512. 
46. Power D. J., Sharda R. and Burstein F. (2015). Decision Support Systems, Joh Wiley \& Sons.

47. Frank J. S. (2015). Competition Concerns in MultiSided Markets in Mobile Communication. Competition on the Internet, pp. 81-99.

48. Giupponi C. (2011). Using Modern Decision Support Systems for Evidence Based Policy Making in IWRM in Developing Countries. available at: http://splash-era.net/index.php

49. McIntosh B., Voinov A., Smith C., and Giupponi C. (2006). Bridging the Gaps between Design and Use: Developing Appropriate Tools for Environmental Management and Policy, in Voinov A., Jakeman A., Rizzoli A. (Eds.), Proceedings of the iEMSs Third Biennial Meeting: "Summit on Environmental Modelling and Software" Burlington, USA, p. 6.

50. UN (2015). Sendai Framework for Disaster Reduction 2015-2030, Third United Nations World Conference, March 18, 2015, Sendai, Japan.

51. Madsen H., Lawrence D., Lang M., Martinkova M., Kjeldsen T. R. (2014). Review of trend analysis and climate change projections of extreme precipitation and floods in Europe, Journal of Hydrology, 519, 3634-3650.

52. Kundzewicz Z. W. (2012). Changes in Flood Risk in Europe. IAHS Special Publication 10, pp. 516.

53. Loucks D. P., Kindler J., Fedra K. (1985). Interactive water resources modeling and model use: an overview. Water Resources Research, 21, pp. 95102.

54. Muste M. (2012). Toward a Watershed-focused Decision Support System. Iowa Water Conference, Ames, Iowa, USA, March 5-7.

55. Abbott, M. B. (1994). Hydroinformatics: A copernican revolution in hydraulics. Journal of Hydraulic Engineering 32, 3-13. 